\title{
Phylogenetic relationships, origin and historical biogeography of the genus Sprattus (Clupeiformes: Clupeidae)
}

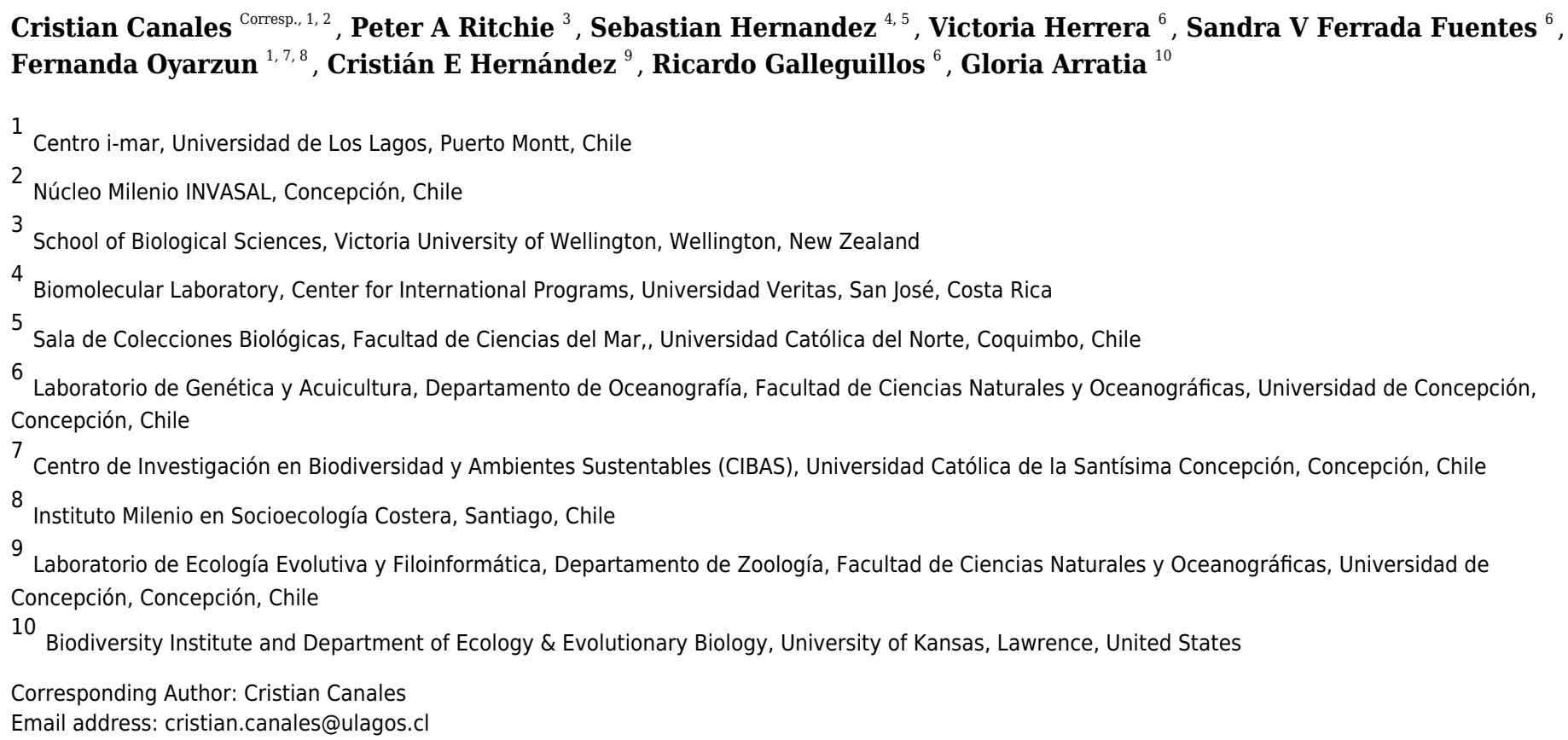

The genus Sprattus comprises five species of marine pelagic fishes distributed worldwide in antitropical, temperate waters. Their distribution suggests an ancient origin during a cold period of the earth's history. In this study, we evaluated this hypothesis and corroborated the non-monophyly of the genus Sprattus, using a phylogenetic approach based on DNA sequences of five mitochondrial genome regions. Sprattus sprattus is more closely related to members of the genus Clupea than to other Sprattus species. We also investigated the historical biogeography of the genus, with the phylogenetic tree showing two well-supported clades corresponding to the species distribution in each hemisphere. Time-calibrated phylogenetic analyses showed that an ancient divergence between Northern and Southern Hemispheres occurred at 55.8 MYBP, followed by a diversification in the Oligocene epoch in the Northern Hemisphere clade (33.8 MYBP) and a more recent diversification in the Southern Hemisphere clade (34.2 MYBP). Historical biogeography analyses indicated that the most recent common ancestor (MRCA) likely inhabited the Atlantic Ocean in the Southern Hemisphere. These results suggest that the ancestral population of the MRCA diverged in two populations, one was dispersed to the Northern Hemisphere and the other across the Southern Hemisphere. Given that the Eocene was the warmest epoch since the Paleogene, the ancestral populations would have crossed the tropics through deeper cooler waters, as proposed by the isothermal submergence 
hypothesis. The non-monophyly confirmed for the genus Sprattus indicates that its systematics should be re-evaluated. 
1 Phylogenetic relationships, origin and historical biogeography of the

2 genus Sprattus (Clupeiformes: Clupeidae)

3

4 Cristian B. Canales-Aguirre ${ }^{1,2}$, Peter A. Ritchie ${ }^{3}$, Sebastián Hernández ${ }^{4,5}$, Victoria Herrera-

5 Yañez $^{6}$, Sandra Ferrada-Fuentes ${ }^{6}$, Fernanda X. Oyarzún ${ }^{1,7,8}$, Cristián E. Hernández ${ }^{9}$, Ricardo

6 Galleguillos $^{6}$, Gloria Arratia ${ }^{10}$

7

8 Running title: Phylogenetic relationships of the genus Sprattus

9

Canales-Aguirre et al.

${ }^{1}$ Centro i mar, Universidad de Los Lagos, Camino a Chinquihue $6 \mathrm{~km}$, Puerto Montt, Chile.

2 Núcleo Milenio INVASAL, Concepción, Chile

$14{ }^{3}$ School of Biological Sciences, Victoria University of Wellington, P.O. Box 600, Wellington, 15 New Zealand.

$16{ }^{4}$ Biomolecular Laboratory, Center for International Programs, Universidad Veritas, 10105 San

17 José, Costa Rica.

18 Sala de Colecciones Biológicas, Facultad de Ciencias del Mar, Universidad Católica del Norte, 191780000 Coquimbo, Chile.

$20{ }^{6}$ Laboratorio de Genética y Acuicultura, Departamento de Oceanografía, Facultad de Ciencias

21 Naturales y Oceanográficas, Universidad de Concepción, Casilla 160-C. Concepción, Chile.

$22{ }^{7}$ Facultad de Ciencias y Centro de Investigación en Biodiversidad y Ambientes Sustentables

23 (CIBAS), Universidad Católica de la Santísima Concepción, Casilla 297, Concepción, Chile.

$24{ }^{8}$ Instituto Milenio en Socioecología Costera, Santiago, Chile.

$25{ }^{9}$ Laboratorio de Ecología Evolutiva y Filoinformática, Departamento de Zoología, Facultad de

26 Ciencias Naturales y Oceanográficas, Universidad de Concepción, Casilla 160-C. Concepción,

27 Chile.

$28{ }^{10}$ Biodiversity Institute and Department of Ecology \& Evolutionary Biology, University of

29 Kansas, Lawrence, KS, USA.

Corresponding Author: Cristian B. Canales-Aguirre, Centro i mar, Universidad de Los Lagos,

33 Camino a Chinquihue 6 km, Puerto Montt, Chile. Phone: (56) 65-2322459, e-mail:

34 cristian.canales@ulagos.c1 


\section{Abstract}

38 The genus Sprattus comprises five species of marine pelagic fishes distributed worldwide in antitropical, temperate waters. Their distribution suggests an ancient origin during a cold period

40 of the earth's history. In this study, we evaluated this hypothesis and corroborated the non41 monophyly of the genus Sprattus, using a phylogenetic approach based on DNA sequences of

42 five mitochondrial genome regions. Sprattus sprattus is more closely related to members of the 43 genus Clupea than to other Sprattus species. We also investigated the historical biogeography of 44 the genus, with the phylogenetic tree showing two well-supported clades corresponding to the 45 species distribution in each hemisphere. Time-calibrated phylogenetic analyses showed that an 46 ancient divergence between Northern and Southern Hemispheres occurred at 55.8 MYBP, 47 followed by a diversification in the Oligocene epoch in the Northern Hemisphere clade (33.8 48 MYBP) and a more recent diversification in the Southern Hemisphere clade (34.2 MYBP). 49 Historical biogeography analyses indicated that the most recent common ancestor (MRCA) 50 likely inhabited the Atlantic Ocean in the Southern Hemisphere. These results suggest that the 51 ancestral population of the MRCA diverged in two populations, one was dispersed to the 52 Northern Hemisphere and the other across the Southern Hemisphere. Given that the Eocene was 53 the warmest epoch since the Paleogene, the ancestral populations would have crossed the tropics 54 through deeper cooler waters, as proposed by the isothermal submergence hypothesis. The non55 monophyly confirmed for the genus Sprattus indicates that its systematics should be re56 evaluated.

57

58 Keywords: BEAST, antitropical distribution, sprat, molecular clock, Clupea. 59 


\section{Introduction}

61 Antitropical distribution patterns - when closely related taxa have geographic distributions to the

62 north and south of the tropics, but not within - are an active line of research in evolutionary

63 biogeography that can benefit greatly from using congeneric species in phylogenetic context.

64 Congeneric species share a common history from their ancestral population, and several studies

65 have shown that the combined analyses of biogeographic history and time-calibrated phylogenies

66 in congeneric species provide a greater insight into the evolutionary processes involved (e.g.,

67 Lavoué et al., 2013). There are still important ecological and commercial fish genera with

68 antitropical distribution patterns that remain to be studied, such as the genus Sprattus.

69 The five extant species currently assigned to the genus Sprattus (Figure 1; Clupeiformes,

70 Clupeidae, Clupeinae) are small marine pelagic fishes that inhabit coastal areas and are well

71 known for their schooling behavior (Whitehead, 1988; Fricke, Eschmeyer \& Van der Laan,

72 2021). They are important components of several food webs and some species are commercially

73 important (Frederiksen et al., 2006). These species occur in cooler waters and have an

74 antitropical distribution (Whitehead, 1988; Figure 1). Sprattus sprattus (Linnaeus, 1758) is the

75 most widely distributed species, and it is the only species in the genus found in the Northern

76 Hemisphere, mainly around the coasts of Europe (Whitehead, 1988; Fricke, Eschmeyer \& Van

77 der Laan, 2021). Sprattus fuegensis (Jenyns, 1842) is found on the South American coast, mainly

78 in the Patagonian shelf from the Pacific and Atlantic Oceans (Whitehead, 1988; Aranis et al.,

79 2007; Canales-Aguirre et al., 2016; Fricke, Eschmeyer \& Van der Laan, 2021). The other three

80 species are found in Oceania: S. novaehollandiae (Valenciennes, 1847) in south-eastern

81 Australia, and S. antipodum (Hector, 1872) and S. muelleri (Klunzinger, 1879) on the coast of

82 New Zealand (Whitehead, Smith \& Robertson, 1985; Whitehead, 1988; Fricke, Eschmeyer \&

83 Van der Laan, 2021).

84 Phylogenetic analyses have shown that the genus Sprattus is sister to the genus Clupea

85 (Lavoué et al., 2007; Li \& Ortí, 2007), and it has been suggested that they diversified between

86 2.66-6.75 MYBP (Jérôme et al., 2003; Cheng \& Lu, 2006), which is consistent with the Miocene

87 record of Clupea. Moreover, the extant Clupea species are thought to have radiated during the

88 Pliocene (3.3-3.5 MYBP; Grant, 1986; Wilson, Teugels \& Meyer, 2008), which is when the

89 genus Sprattus is thought to have diverged. More recent studies based on large fossil-calibrated

90 phylogenies suggested that the genus Sprattus is a paraphyletic group, and S. sprattus is more 
91 closely related to Clupea spp. than to its relatives in the Southern Hemisphere (Lavoué et al.,

92 2013; Bloom \& Lovejoy, 2014; Egan et al., 2018).

93 No study has examined the biogeographic origin of the genus Sprattus; though, information

94 of species with similar antitropical distribution pattern have been conducted. For example,

95 studies of extant populations of Sardinops species showed a recent diversification event between

96 0.2-2 MYBP (Grant \& Leslie, 1996; Bowen \& Grant, 1997; Grant \& Bowen, 1998), whereas

97 species included in the genus Engraulis diversified between 5-10 MYBP (Grant, Leslie \&

98 Bowen, 2005). When considering marine species that have an antitropical distribution, the

99 tropical zone appears to act as a barrier to long-distance dispersal, restricting gene flow between

100 the Northern and Southern Hemispheres (Grant, Lecomte \& Bowen, 2010). Experimental studies

101 aiming to evaluate the thermal tolerance of two temperate species of Clupeidae (e.g., Clupea

102 harengus and Sardinops sagax) evidenced their low tolerance for warm (tropical) waters

103 (Martínez-Porchas, Hernández-Rodríguez \& Bückle-Ramírez, 2009; Peck et al., 2012). These

104 results reinforce the hypothesis that warm waters act as a dispersal barrier.

105 Considering the current antitropical distribution pattern of the genus Sprattus, we

106 hypothesize that the lower sea temperatures of the tropics during the cooler glacial periods

107 between the Miocene and Pliocene might have provided a window of opportunity for the most

108 recent common ancestor of Sprattus to disperse to the other hemisphere. In this study we test the

109 origin and the monophyly of the genus Sprattus using a phylogenetic approach based on DNA

110 sequences from five mitochondrial genome regions (mtDNA). We also examine the historical

111 biogeography of the group, and we used a molecular clock to determine the pattern and timing of

112 species diversification.

113

114

\section{Materials and Methods}

\section{Taxon sampling}

117 Sprattus species have a least concern status for the IUCN Red List and are not listed under

118 CITES. We did not kill fishes for the purpose of this study; instead, tissue samples were provided

119 by researchers worldwide. Unfortunately, samples for Sprattus novaehollandiae were impossible

120 to obtain, therefore we used only three Sprattus species from the Southern Hemisphere. All

121 tissue samples arrived fixed in ethanol 90\%, and their general capture locations were S. fuegensis

Peer] reviewing PDF | (2020:09:53259:2:0:NEW 12 Jun 2021) 
$122(\mathrm{n}=7)$ from Chilean fjords in the Southeast Pacific Ocean, S. sprattus $(\mathrm{n}=5)$ from Norwegian

123 fjords in the Northeast Atlantic Ocean, S. muelleri $(\mathrm{n}=4)$ from Auckland Harbour, and $S$.

124 antipodum $(\mathrm{n}=1)$ from Wellington Harbour (New Zealand).

125

126 DNA extraction, PCR and DNA sequencing

127 Total genomic DNA was dissolved in a buffer containing proteinase K and SDS detergent, and

128 then extracted using a standard phenol-chloroform protocol (Sambrook et al., 1989). DNA was

129 precipitated in $70 \%$ ethanol and resuspended in $50 \mu \mathrm{L}$ of TE buffer. DNA was quantified using a

130 NanoDrop ND-1000 spectrophotometer and diluted to a concentration of $20 \mathrm{ng} / \mu \mathrm{L}$.

131 Five mitochondrial fragments were amplified using genus-specific primers (762 bp for

132 Cytochrome b, CytB; 857 bp for Cytochrome Oxidase subunit I, COI; 827 bp for NADH

133 dehydrogenase subunit 2, ND2; and 348 bp for NADH dehydrogenase subunit 3, ND3) designed

134 in this study, and one primer pair described previously (1107 bp for Control Region, CR;

135 Palumbi et al., 1991; Bernatchez, Guyomard \& Bonhomme, 1992; see Supporting Information

136 Table S1). The genus-specific primers were designed from the complete mitochondrial genomes

137 sequences deposited in GenBank: Sprattus sprattus (NC009593), S. muelleri (NC16669) and S.

138 antipodum (NC16673). For CytB, COI, ND2, and ND3 fragments, the PCRs were conducted in

$13930 \mu \mathrm{L}$ volumes containing 1X PCR Buffer (Invitrogen ${ }^{\circledR}$; Tris-HCl 200 mM, pH 8,4, KCl, 500

$140 \mathrm{mM}$ ), $3 \mathrm{mM} \mathrm{MgCl} 2,0.2 \mathrm{mM}$ of each dNTP's, $0.2 \mu \mathrm{M}$ of each primer, $0.4 \mathrm{mg} / \mathrm{mL}$ of BSA, 1.5

141 units of Taq DNA polymerase (Invitrogen ${ }^{\circledR}$ ), and 2 ng of genomic DNA. Thermal cycling was

142 performed in an MJ Research PTC-200 Thermal Cycler with the following parameters: $95^{\circ} \mathrm{C}$ for

$143180 \mathrm{~s}$, followed by 35 cycles of $94^{\circ} \mathrm{C}$ for $30 \mathrm{~s}, 55^{\circ} \mathrm{C}$ for $30 \mathrm{~s}, 74^{\circ} \mathrm{C}$ for $60 \mathrm{~s}$, and a final

144 extension at $74^{\circ} \mathrm{C}$ for $300 \mathrm{~s}$. For CR the PCR was amplified using $2 \mathrm{mM} \mathrm{MgCl}_{2}$ and the thermo

145 cycling parameters: $94^{\circ} \mathrm{C}$ for $300 \mathrm{~s}$, followed by 35 cycles of $94^{\circ} \mathrm{C}$ for $30 \mathrm{~s}, 54^{\circ} \mathrm{C}$ for $60 \mathrm{~s}, 74^{\circ}$

$146 \mathrm{C}$ for $90 \mathrm{~s}$, and a final extension at $74^{\circ} \mathrm{C}$ for $600 \mathrm{~s}$. PCR products were purified with ExoSAP-

147 IT ${ }^{\circledR}$ following manufacturer's guidelines and sequenced in both directions using an ABI 3730x1

148 Genetic Analyzer (Massey University Genome Sequencing Service). Sequences were deposited

149 in GenBank database under the accession numbers MW075156-MW075219. Additional

150 sequences to genus Sprattus were included in the ingroup for further analyses: i) Clupea

151 harengus (KC193777) and Clupea pallasii (AP009134), including two herring subspecies from

152 C.pallasii (C.p. marisalbi and C.p. suworowi), given their close relatedness to the genus

Peer] reviewing PDF | (2020:09:53259:2:0:NEW 12 Jun 2021) 
153 Sprattus; ii) Ethmidium maculatum (AP011602), Ramnogaster melanostoma (GQ890211-

154 GQ890214, KU288994- KU288995), and Strangomera bentincki (GenBank accession numbers

155 solicited), given their close relatedness with the Sprattus-Clupea clade; iii) Potamalosa

156 richmondia (AP011594) and Hyperlophus vittatus (AP011593), because they are more distantly

157 related genera to the Sprattus-Clupea clade; and iv) Sprattus sprattus (AP009234), Sprattus

158 muelleri (AP011607), and Sprattus antipodum (AP011608) to increase the number of sequences

159 of our target genus. As outgroups, we included Gilchristella aestuaria (AP011606) and Ehirava

160 fluviatilis (AP011588), two species of the subfamily Ehiravinae used for rooting and time

161 calibration purposes.

162 Initial alignment was performed in Geneious ${ }^{\circledR}$ 6.0.5 (Kearse et al., 2012), and the final

163 alignment was adjusted by eye. Phylogenetic analyses were conducted separately on each gene

164 (to compare each gene tree) and concatenated fragments (because mitochondrial DNA

165 constitutes a single heritable unit). Divergence time and historical biogeography analyses were

166 conducted using a concatenated alignment of the five mitochondrial fragments. Our concatenated

167 data matrix included 13 sequences (one taxa each) and 3228 characters.

168

\section{Phylogenetic analyses and divergence time}

170 Before conducting the phylogenetic analyses, we performed Xia's test implemented in DAMBE

171 v5 (Xia et al., 2003; Xia, 2013) to evaluate whether the DNA sequences we used showed

172 evidence of saturation by substitution (i.e., back mutations), which would need to be corrected

173 using a model of sequence evolution during the phylogenetic analyses. We estimated and

174 compared a substitution saturation index with a critical substitution saturation index (Xia et al.,

175 2003; Xia, 2013) to test that the data set is informative for performing phylogenetic analyses.

176 The results of Xia's test suggest that there is a low level of saturation in our data set, where the

177 critical index of substitution saturation values was significantly higher than the observed index of

178 substitution saturation values (Supporting Information Table S2).

179 We ran a Bayesian Markov Chain Monte Carlo (BMCMC) phylogenetic analysis that

180 included a general likelihood-based mixture model of gene-sequence evolution and a Reversible-

181 Jump Markov Chain Monte Carlo procedure (Pagel \& Meade, 2004, 2006, 2008; Gascuel, 2005).

182 This phylogenetic reconstruction was implemented in BayesPhylogenies v1.1 software (Pagel \&

183 Meade, 2004). This approach enables possible models and parameters to be explored, converging 
184 towards the model that best fits the data in the sample of posterior trees (Pagel \& Meade, 2008).

185 We ran five independent chains using $10^{6}$ generations, sampling every $10,000^{\text {th }}$ tree sample, and

186 burning the first $25 \%$ of the trees. Finally, we obtained the phylogenetic consensus tree using 187750 tree samples.

188 Approximate divergence times among Sprattus species were estimated using a Bayesian 189 approach implemented in the BEAST v2 software (Heled \& Drummond, 2008; Drummond et al., 190 2012; Bouckaert et al., 2014). To obtain divergence times, we used the Log-Normal Relaxed 191 Clock Model (LNCM; Drummond et al., 2006; Drummond \& Suchard, 2010). We ran this model 192 five times using the most complex sequence evolution model, GTR+I+G, with 10,000,000 193 generations sampling each 10,000 generations. The outputs of each run were combined in 194 LogCombiner software to increase the Effective Sample Size (ESS) to be at least $>200$. The ESS 195 of a parameter sampled from an MCMC is the number of effectively independent draws from the 196 posterior distribution of the Markov Chain.

197 To obtain the posterior distribution of the estimated divergence time, the age of a fossil, $198 \dagger$ Lecceclupea ehiravaensis, dated during the late Campanian in the Late Cretaceous epoch at 199 about 74 MYBP was used. (Taverne, 2011 interpreted this age as part of the Campanian200 Maastrichtian; however, 74 MYBP is currently considered within the Campanian according to 201 the ICS International Chronostratigraphic Chart, 2021; www.stratigraphy.org.) This age was 202 used as a calibration point to constrain the age in the Gilchristella aestuaria and Ehirava 203 fluviatilis node. $\dagger$ Lecceclupea ehiravaensis has been shown to be a crown member of the clade 204 (Ehirava, Gilchristella; see Taverne, 2011). Prior age distribution of this clade follows a 205 lognormal distribution using the age boundaries of the geological stage from which the fossil was 206 excavated (i.e., 95\% credibility interval). An offset of 74 MYBP was applied to the model.

207 Subsequently, we used the Log-Normal Relaxed Clock Model and previous set parameters to run 20810 independent Markov Chain Monte Carlo (MCMC) simulations with a chain length of $10^{7}$ 209 generations. Sampling was conducted every 10,000 generations and we used as prior 210 distributions the following parameters: the base frequency, proportion invariant sites, and 211 proportions of each transition and transversion, all of those to increase the effective sample size.

212 The individual runs were combined using LogCombiner burning 250 trees per each sample.

213 Finally, a maximum clade credibility tree was created in TreeAnnotator, which enable a 214 summary tree to be visualized in FigTree v1.4 (https://github.com/rambaut/figtree/releases). 


\section{Historical biogeography}

217 We inferred the historical distribution of the genus Sprattus and its close relatives using their

218 current distribution (i.e., longitude and latitude as continuous traits). This approach was chosen

219 over the multistate discrete data for the following reasons: i) discrete data could bias the

220 ancestral state of a descendant species distributed in the same geographical region; ii) continuous

221 data permit identifying dispersal trends; and iii) classical discrete multistate estimation does not

222 consider the spherical nature of the earth (O’Donovan, Meade \& Venditti, 2018; Gardner, Surya

223 \& Organ, 2019; Avaria-Llautureo et al., 2020). For these, we used the current geolocation to

224 infer the ancestral distribution for each node of the phylogenetic tree. To reconstruct the

225 distribution, we used the Geo Model (O’Donovan, Meade \& Venditti, 2018) and implemented

226 BayesTraits v3.0 (Pagel \& Meade, 2004). The Geo Model estimates the posterior distribution of

227 their geo-position across phylogenetic nodes. We used tree samples obtained in BMCMC

228 phylogenetic analyses and a trait matrix. We ran $10^{6}$ generations sampled every 10,000

229 generations to obtain a parameters sample. Posteriorly, a 25\% burned-in was used to avoid

230 including parameters sampled before the convergence of the Markov Chain, and a final sample

231 of 750 parameters was obtained. The ancestral distribution of each node was plotted on a

232 paleogeographical perspective using mapast v0.1 R package (Varela \& Rothkugel, 2018). We

233 combine paleomaps from 10, 30, 50, 90, 110 MYBP using SETON2012 as a global plate motion

234 model (Seton et al., 2012).

235

236

\section{Results}

238 Phylogenetic tree reconstructions using the concatenated fragments (Figure 2) and each

239 mitochondrial fragment independently showed a similar pattern (Supporting Information Figure

240 S1). Each extant Sprattus species forms a monophyletic group. The Sprattus species were

241 distributed in the phylogenetic tree in two main clades that matched their antitropical

242 distribution, each in one hemisphere. The Northern Hemisphere clade included Sprattus sprattus

243 and the species Clupea harengus and C.pallasii (including their subspecies); the Southern

244 Hemisphere clade included Sprattus fuegensis, S. antipodum, S. muelleri, Ramnogaster

245 melanostoma, and Strangomera bentincki. However, overall, the genus Sprattus is polyphyletic, 
246 because $S$. sprattus is closely related to Clupea and S. fuegensis, whereas S. antipodum and $S$.

247 muelleri are closely related to Ramnogaster and Strangomera.

248 The time-calibrated phylogenetic analyses showed a divergence between Northern and

249 Southern Hemispheres that was dated at 55.8 MYBP (early Eocene; Figure 3A). There was also

250 another diversification event among the Northern Hemisphere clade at 33.8 MYBP (boundary

251 between Eocene and Oligocene), splitting Sprattus sprattus from Clupea species. Current species

252 of Clupea diverged about 8.5 million years ago (late Miocene). For the Southern Hemisphere

253 clade, species diverged at 33.2 MYBP (early Oligocene). Among the species of the Southern

254 Hemisphere clade, Strangomera bentincki split from other Sprattus species around 22.6 MYBP

255 (early Miocene), Sprattus fuegensis split at 13.3 MYBP (middle Miocene) from their New

256 Zealand relatives, and the most common recent ancestor of S. antipodum and S. muelleri

257 diverged around 5.6 MYBP (boundary between Miocene and Pliocene). Ancestral distributions

258 (Figure 3B-G) show that the MRCA of the Northern and Southern clades likely inhabited the

259 Southern Hemisphere in the Atlantic Ocean (Figure 3D).

260

261

\section{Discussion}

263

264 Non-monophyletic genus Sprattus

265 We confirmed that the genus Sprattus is a polyphyletic group with an antitropical distribution,

266 challenging the taxonomic status of the Sprattus species. Considering the two geographic clades

267 in opposing hemispheres, the Northern clade closely relates S. sprattus with the genus Clupea,

268 and the Southern clade closely relates the rest of Sprattus members with Strangomera bentincki

269 and Ramnogaster melanostoma. The relationship among species from the Southern clade has not

270 been described before. This taxonomic incongruence in the genus Sprattus has also been

271 identified in studies that use large phylogenies in Clupeiformes and have focused in the

272 identification of the biogeographic or diadromy origin, body size, dispersal pattern, or trophic

273 niche evolution of the group (Lavoué et al., 2013; Bloom \& Lovejoy, 2014; Egan et al., 2018;

274 Bloom, Burns \& Schriever, 2018; Avaria-Llautureo et al., 2020). Although some of these studies

275 are based on DNA of different types (i.e., mt or nDNA) or taxa (i.e., Sprattus members and its

276 close relatives), they support the polyphyly of the genus Sprattus. Therefore, our results provide 
277 further support for Sprattus being polyphyletic and add S. fuegensis and Strangomera bentincki

278 as pieces of the puzzle to understand the evolution in the Southern clade.

279 Taxonomic classification and phylogenetic relationships among the genera Sprattus,

280 Ramnogaster, Strangomera, and Clupea are unclear if they are only based on morphological and

281 meristic traits. All these taxa resemble the Clupea type and were first classified as species of

282 Clupea (Linnaeus 1758; Whitehead, Smith \& Robertson, 1985; Whitehead, 1988). The genus

283 Sprattus was erected by Girgensohn (1846) based on S. haleciformis, which was later

284 synonymized with $S$. sprattus (Whitehead, 1988), defining the absence of a pterotic bullae as the

285 key diagnostic feature (Mathews, 1884; Whitehead, 1964, 1988; Whitehead, Smith \& Robertson,

286 1985). However, fewer pelvic rays and an anteriorly placed pelvic fin (Whitehead, 1988) have

287 also been used to differentiate Sprattus from Clupea. The two genera also differentiate in key

288 reproductive traits, whereas Sprattus produces pelagic eggs, Clupea produces demersal eggs that

289 attach to the seabed or vegetation (Haegele \& Schweigert, 1985; Whitehead, 1988). Finally, the

290 genera Sprattus and Ramnogaster share the absence of a pterotic bullae, but differ in fin-ray

291 numbers (Whitehead, 1988), whereas Sprattus differs from Strangomera on having more gill

292 rakers (Whitehead, 1988).

293 Incomplete sorting lineage, introgression, or convergence of morphological traits could

294 be plausible explanations for the current Sprattus taxonomic classification and our gene tree. The

295 first two can be ruled out, because none of the species of this study shared or had similar

296 haplotypes. Introgression may also be ruled out, because the fishes have different reproductive

297 strategies: pelagic or demersal eggs (Haegele \& Schweigert, 1985; Whitehead, 1988), so there is

298 little opportunity for cross-fertilization. However, introgression could be true if divergence in

299 reproductive ecology occurred at an initial stage older than 33.8 MYBP between S. sprattus and

300 Clupea species. Introgression and ancient hybridization events could be identified by comparing

301 mtDNA and nDNA (Saitoh et al., 2011), however, this has not been detected in clupeid

302 phylogenies (Bloom \& Lovejoy, 2014). We cannot discard the convergence of morphological

303 traits explanation given that there are traits that look similar and others that support the

304 separation of Sprattus and Clupea (Mathews, 1884; Whitehead, 1964, 1988; Whitehead, Smith \&

305 Robertson, 1985).

306 For Sprattus species from the Southern Hemisphere, we found that S. fuegensis from South

307 America is the sister to New Zealand's sympatric S. antipodum and S. muelleri. Nonetheless, we 
308 need to keep in mind that we could not include $S$. novaehollandiae, hence further studies should

309 include this species. For New Zealand sprats, it only has been suggested that these species might

310 have different ecological requirements considering their sympatry (Whitehead, Smith \&

311 Robertson, 1985). We suggest that further investigations be done to disentangle the mechanisms

312 that promoted sympatric speciation for S. antipodum and S. muelleri.

313

314 Divergence time and historical biogeography

315 The results based on a fossil calibration showed that the two antitropical clades diverged in the

316 Eocene (55.8 MYBP; older than we hypothesized), with a likely origin in the Atlantic Ocean in

317 the Southern Hemisphere. The species within the Northern Hemisphere clade diverged at 33.8

318 and in the Southern Hemisphere at 33.4 MYBP, during the early Oligocene. Cheng et al. (2006)

319 and Jérôme et al. (2003) estimated that the divergence event of the two genera occurred between

320 6.75-2.66 MYBP (late Neogene-early Quaternary). This estimation disagrees with the older

321 divergence time found in our study, which could be explained by the calibrating method used by

322 the authors. Different calibrating methods typically yield different results, and each method has

323 its own particular challenges. In previous studies the authors used a standard nucleotide

324 substitution rate for fish, which is a method that depends on the timescale over which those rates

325 are measured (Hipsley \& Müller, 2014) and could generate an overestimation of divergence

326 times (Phillips, 2009; Ho et al., 2011; Hipsley \& Müller, 2014). Fossil calibrations do not

327 produce this problem, although the uncertainty in age and phylogenetic position present a

328 different challenge (Hipsley \& Müller, 2014). To address this and avoid the overestimation of the

329 divergence time, we ran our analysis based on the fossilized birth-death process calibration

330 method and a Bayesian framework, which included the uncertainty of dating species divergences

331 and yield with more accurate node age estimates (Heath, Huelsenbeck \& Stadler, 2014;

332 Bouckaert et al., 2014; Gavryushkina et al., 2017).

333 The Eocene was the warmest geological epoch of the last 65 million years (Zachos et al., 334 2001), where sea surface temperatures in the Atlantic tropical areas may have been up to $38^{\circ} \mathrm{C}$

335 (Cramwinckel et al., 2018). The ancestor of Clupeoidei originated and diversified in the tropical

336 Indo-West Pacific region during the Lower Cretaceous (119 MYBP, Lavoué et al., 2013), and it

337 would have been adapted to warm, marine temperatures (i.e., $>25^{\circ}$ C; Lavoué et al., 2013;

338 Bloom \& Lovejoy, 2014). Considering this, our analyses show that the Clupeidae lineage spread 
339 to the Southern Hemisphere earlier than the clades that included Sprattus, Clupea and close 340 relatives. Similarly, the species of Potamalosa, Hyperlophus and Ethmidium also inhabit

341 temperate waters in the Southern Hemisphere, suggesting that this old south-distributed group of

342 fishes was able to cross the tropics but not to adapt to the warmer environment. Nonetheless,

343 extant members of the genera Sprattus and Clupea are now distributed antitropically in much

344 colder temperate waters (Whitehead, Smith \& Robertson, 1985; Lavoué et al., 2013), and

345 although they mainly inhabit marine environments (Bloom \& Lovejoy, 2014), they can also

346 inhabit areas with highly variable environments, such as fjords (e.g., Glover et al., 2011;

347 Canales-Aguirre et al., 2016, 2018).

348 Antitropical distribution patterns are traditionally explained by dispersal and vicariance 349 mechanisms (Stepien \& Rosenblatt, 1996; Grant \& Bowen, 1998; Burridge, 2002; Le Port, 350 Pawley \& Lavery, 2013). Dispersalists have proposed several hypotheses to explain dispersal 351 across the tropics: island integration (Rotondo et al., 1981), dispersal at shallow depths during 352 glaciations (Lindberg, 1991), and isothermal submergence (Hubbs, 1952). Island integration 353 refers to the formation of endemic biotas through the movement of individuals using islands or 354 seamounts (Rotondo et al., 1981). In our case, we can discard this explanation, because clupeids 355 are typically marine and inhabit productive coastal areas (Whitehead, 1988). Dispersal at shallow 356 depths during glaciations is a well-recognized dispersal mechanism for several pelagic fishes 357 during the Pleistocene (Burridge \& White, 2000; Burridge, 2002; Grant, Leslie \& Bowen, 2005).

358 The isothermal submergence hypothesis refers to the possibility that marine organisms adapted 359 to cool or temperate areas are able to disperse across the tropical region through deeper, colder 360 tropical waters (Hubbs, 1952). Taking into account that the MRCA of these two clades 361 diversified in the warm Eocene, and then each clade diversified between the late Eocene and 362 early Oligocene epochs the isothermal submergence hypothesis seems to be the most plausible 363 explanation. This later because the temperatures begin to decrease until initiation of Antarctic 364 glaciation (Zachos et al., 2001) and some clupeoids, such as herrings, may dive as much as 200 365 m (Blaxter, Denton \& Gray, 1981). Vicariant mechanisms such as plate tectonic, relictual 366 distribution, and equatorial isolation by climatic change or biological interactions have been 367 advocated by others studies (Stepien \& Rosenblatt, 1996; Saitoh et al., 2011). However, 368 mechanisms associated with plate tectonics are not supported by our results, because the 369 divergence time among nominal species of Sprattus and Clupea would have occurred during the 
370 Eocene, and the present continental configuration closely resembles the configuration of the

371 continents during that time. Studies, such as those by Grant \& Bowen (1998) and Grant, Leslie \&

372 Bowen (2005) on marine pelagic fishes have supported a dispersalist mechanism to explain the

373 antitropical distribution and exclude vicariant explanations as well.

374 Dispersion from their ancestral habitat involved adaptation to colder waters, while

375 simultaneously expanding their tolerance to fluctuations in salinity, allowing them to also

376 colonize low saline habitats. The warmer equatorial waters have remained as a key barrier to

377 dispersal between hemispheres, which has only been crossed when windows of colder

378 environments appeared across the tropics or, more plausibly, by using deeper, colder tropical

379 waters as proposed by the isothermal submergence hypothesis.

380

381

382 Acknowledgements

383 Authors are grateful to Jeff Shima from Victoria University of Wellington, Tom Trnski from 384 Auckland War Memorial Museum, and Malcom Francis from National Institute of Water and 385 Atmospheric Research (NIWA) all of them from New Zealand; Kevin Glover from Institute of 386 Marine Research from Norway, and Anna Semenova from Moscow State University from 387 Russia, for sharing tissue samples of the genera Sprattus or Clupea. We thank Sébastien Lavoué 388 and one anonymous reviewer for providing valuable comments on earlier versions of the 389 manuscript and Terry J. Meehan (Lawrence, Kansas, USA) for checking and improving the 390 language or the English style.

391

392

\section{References}

394 Aranis A, Meléndez R, Pequeño G, Cerna F. 2007. Sprattus fuegensis en aguas interiores de 395 Chiloé, Chile (Osteichthyes: Clupeiformes: Clupeidae). Gayana 71:102-113.

Avaria-Llautureo J, Venditti C, Rivadeneira MM, Inostroza-Michael O, Rivera RJ, Hernández CE, Canales-Aguirre CB. 2020. Shrinking of fish under warmer temperatures decrease dispersal abilities and speciation rates. Biorxiv:1-18. DOI: 10.1101/2020.10.27.357236.

Bernatchez L, Guyomard R, Bonhomme F. 1992. DNA sequence variation of the mitochondrial control region among geographically and morphologically remote European brown trout 
401

402

403

404

405

406

407

408

409

410

411

412

413

414

415

416

417

418

419

420

421

422

423

424

425

426

427

428

429

430

431

Salmo trutta populations. Molecular Ecology 1:161-173.

Blaxter JHS, Denton EJ, Gray JAB. 1981. Acousticolateralis system in clupeid fishes. In: Tavolga WN, Popper AN, Fay RR eds. Hearing and Sound Communication in Fishes. Springer, New York, NY, 39-59.

Bloom DD, Burns MD, Schriever TA. 2018. Evolution of body size and trophic position in migratory fishes: a phylogenetic comparative analysis of Clupeiformes (anchovies, herring, shad and allies). Biological Journal of the Linnean Society 125:302-314.

Bloom DD, Lovejoy NR. 2014. The evolutionary origins of diadromy inferred from a timecalibrated phylogeny for Clupeiformes (herring and allies). Proceedings of the Royal Society B: Biological Sciences 281:20132081. DOI: 10.1098/rspb.2013.2081.

Bouckaert R, Heled J, Kühnert D, Vaughan T, Wu C-H, Xie D, Suchard MA, Rambaut A, Drummond AJ. 2014. BEAST 2: a software platform for Bayesian evolutionary analysis. PLoS Computational Biology 10:e1003537.

Bowen BW, Grant WS. 1997. Phylogeography of the sardines (Sardinops spp.): assessing biogeographic models and population histories in temperate upwelling zones. Evolution $51: 1601-1610$.

Burridge CP. 2002. Antitropicality of Pacific fishes: molecular insights. Environmental Biology of Fishes 65:151-164.

Burridge CP, White RWG. 2000. Molecular phylogeny of the antitropical subgenus Goniistius (Perciformes: Cheilodactylidae: Cheilodactylus): evidence for multiple transequatorial divergences and non-monophyly. Biological Journal of the Linnean Society 70:435-458.

Canales-Aguirre CB, Ferrada-Fuentes S, Galleguillos R, Hernández CE. 2016. Genetic structure in a small pelagic fish coincides with a marine protected area: seascape genetics in Patagonian fjords. PLoS One 11:e0160670.

Canales-Aguirre CB, Ferrada-Fuentes S, Galleguillos R, Oyarzun FX, Buratti CC, Hernández CE. 2018. High genetic diversity and low-population differentiation in the Patagonian sprat (Sprattus fuegensis) based on mitochondrial DNA. Mitochondrial DNA Part A 29:1148-1155. DOI: 10.1080/24701394.2018.1424841.

Cheng QQ, Lu DR. 2006. Phylogenetic analysis and relative-rate test of nine Clupeidae fishes Osteichthyes Clupeiformes inferred from cytochrome b gene sequence of mitochondrial DNA. Marine Fisheries 28:5-12. 
432 Cramwinckel MJ, Huber M, Kocken IJ, Agnini C, Bijl PK, Bohaty SM, Frieling J, Goldner A,

433

434

435

436

437

438

439

440

441

442

443

444

445

446

447

448

449

450

451

452

453

454

455

456

457

458

459

460

461

462

Hilgen FJ, Kip EL, Peterse F, van der Ploeg R, Röhl U, Schouten S, Sluijs A. 2018.

Synchronous tropical and polar temperature evolution in the Eocene. Nature 559:382386.

Drummond AJ, Ho SYW, Phillips MJ, Rambaut A. 2006. Relaxed phylogenetics and dating with confidence. PLoS Biology 4:e88.

Drummond AJ, Suchard MA. 2010. Bayesian random local clocks, or one rate to rule them all. BMC Biology 8:114.

Drummond AJ, Suchard MA, Xie D, Rambaut A. 2012. Bayesian phylogenetics with BEAUti and the BEAST 1.7. Molecular Biology and Evolution 29:1969-1973.

Egan JP, Bloom DD, Kuo C-H, Hammer MP, Tongnunui P, Iglésias SP, Sheaves M, Grudpan C, Simons AM. 2018. Phylogenetic analysis of trophic niche evolution reveals a latitudinal herbivory gradient in Clupeoidei (herrings, anchovies, and allies). Molecular Phylogenetics and Evolution 124:151-161.

Frederiksen M, Edwards M, Richardson AJ, Halliday NC, Wanless S. 2006. From plankton to top predators: bottom-up control of a marine food web across four trophic levels. Journal of Animal Ecology 75:1259-1268.

Fricke R, Eschmeyer W, Van der Laan R. 2021. Eschmeyer's catalog of fishes: genera, species, references. Available at http://researcharchive.calacademy.org/research/ichthyology/catalog/fishcatmain.asp (accessed March 8, 2021).

Gardner JD, Surya K, Organ CL. 2019. Early tetrapodomorph biogeography: controlling for fossil record bias in macroevolutionary analyses. Comptes Rendus Palevol 18:699-709.

Gascuel O. 2005. Mathematics of Evolution and Phylogeny. Oxford University Press Inc. New York, United Stated. 440 pp.

Gavryushkina A, Heath TA, Ksepka DT, Stadler T, Welch D, Drummond AJ. 2017. Bayesian total-evidence dating reveals the recent crown radiation of penguins. Systematic Biology $66: 57-73$.

Glover KA, Skaala Ø, Limborg M, Kvamme C, Torstensen E. 2011. Microsatellite DNA reveals population genetic differentiation among sprat (Sprattus sprattus) sampled throughout the Northeast Atlantic, including Norwegian fjords. ICES Journal of Marine Science

Peer] reviewing PDF | (2020:09:53259:2:0:NEW 12 Jun 2021) 
463

464

465

466

467

468

469

470

471

472

473

474

475

476

477

478

479

480

481

482

483

484

485

486

487

488

489

490

491

492

493

68:2145-2151.

Grant WS. 1986. Biochemical genetic divergence between Atlantic, Clupea harengus, and Pacific, C. pallasi, herring. Copeia 1986:714-719.

Grant WS, Bowen BW. 1998. Shallow population histories in deep evolutionary lineages of marine fishes: insights from sardines and anchovies and lessons for conservation. Journal of Heredity 89:415-426.

Grant WS, Lecomte F, Bowen BW. 2010. Biogeographical contingency and the evolution of tropical anchovies (genus Cetengraulis) from temperate anchovies (genus Engraulis). Journal of Biogeography 37:1352-1362.

Grant WS, Leslie RW. 1996. Late Pleistocene dispersal of Indian-Pacific sardine populations in an ancient lineage of the genus Sardinops. Marine Biology 126:133-142. DOI: 10.1007/bf00571385.

Grant WS, Leslie RW, Bowen BW. 2005. Molecular genetic assessment of bipolarity in the anchovy genus Engraulis. Journal of Fish Biology 67:1242-1265.

Haegele CW, Schweigert JF. 1985. Distribution and characteristics of herring spawning grounds and description of spawning behavior. Canadian Journal of Fisheries and Aquatic Sciences 42:s39-s55.

Heath TA, Huelsenbeck JP, Stadler T. 2014. The fossilized birth-death process for coherent calibration of divergence-time estimates. Proceedings of the National Academy of Sciences of the United States of America 111:E2957-66.

Heled J, Drummond AJ. 2008. Bayesian inference of population size history from multiple loci. BMC Evolutionary Biology 8:289.

Hipsley CA, Müller J. 2014. Beyond fossil calibrations: realities of molecular clock practices in evolutionary biology. Frontiers in Genetics 5:138.

Ho SYW, Lanfear R, Bromham L, Phillips MJ, Soubrier J, Rodrigo AG, Cooper A. 2011. Timedependent rates of molecular evolution. Molecular Ecology 20:3087-3101. DOI: 10.1111/j.1365-294x.2011.05178.x.

Hubbs CL. 1952. Antitropical distribution of fishes and other organisms. Proceedings of the 7th Pacific Science Congress 3:324-329.

Jérôme M, Lemaire C, Bautista JM, Fleurence J, Etienne M. 2003. Molecular phylogeny and species identification of sardines. Journal of Agricultural and Food Chemistry 51:43-50. 
494 Kearse M, Moir R, Wilson A, Stones-Havas S, Cheung M, Sturrock S, Buxton S, Cooper A, 495 Markowitz S, Duran C, Thierer T, Ashton B, Meintjes P, Drummond A. 2012. Geneious 496 Basic: an integrated and extendable desktop software platform for the organization and 497 analysis of sequence data. Bioinformatics 28:1647-1649.

498 Lavoué S, Miya M, Musikasinthorn P, Chen W-J, Nishida M. 2013. Mitogenomic evidence for 499 an Indo-West Pacific origin of the Clupeoidei (Teleostei: Clupeiformes). PLoS One

500 8:e56485.

501

Lavoué S, Miya M, Saitoh K, Ishiguro NB, Nishida M. 2007. Phylogenetic relationships among 502 anchovies, sardines, herrings and their relatives (Clupeiformes), inferred from whole

503 mitogenome sequences. Molecular Phylogenetics and Evolution 43:1096-1105.

504 Le Port A, Pawley MDM, Lavery SD. 2013. Speciation of two stingrays with antitropical 505

506 distributions: low levels of divergence in mitochondrial DNA and morphological characters suggest recent evolution. Aquatic Biology 19:153-165.

Li C, Ortí G. 2007. Molecular phylogeny of Clupeiformes (Actinopterygii) inferred from nuclear 509 and mitochondrial DNA sequences. Molecular Phylogenetics and Evolution 44:386-398.

Lindberg DR. 1991. Marine biotic interchange between the northern and southern hemispheres. Paleobiology 17:308-324.

Martínez-Porchas M, Hernández-Rodríguez M, Bückle-Ramírez LF. 2009. Thermal behavior of the Pacific sardine (Sardinops sagax) acclimated to different thermal cycles. Journal of Thermal Biology 34:372-376.

Mathews D. 1884. Report on sprat fishing during the winter of 1883-84. Report of the Fishery Board for Scotland.

O’Donovan C, Meade A, Venditti C. 2018. Dinosaurs reveal the geographical signature of an evolutionary radiation. Nature Ecology \& Evolution 2:452-458.

Pagel M, Meade A. 2004. A phylogenetic mixture model for detecting pattern-heterogeneity in

520

521

522

523

524 gene sequence or character-state data. Systematic Biology 53:571-581.

Pagel M, Meade A. 2006. Bayesian analysis of correlated evolution of discrete characters by reversible-jump Markov chain Monte Carlo. American Naturalist 167:808-825.

Pagel M, Meade A. 2008. Modelling heterotachy in phylogenetic inference by reversible-jump Markov chain Monte Carlo. Philosophical Transactions of the Royal Society of London. Series B, Biological Sciences 363:3955-3964. 
525 Palumbi SR, Martin A, Romano S, McMillan WO, Stice L, Grabowski G. 1991. Simple fool's 526 guide to PCR. Dept. of Zoology and Kewalo Marine Laboratory, University of Hawaii.

527 Peck MA, Kanstinger P, Holste L, Martin M. 2012. Thermal windows supporting survival of the 528 earliest life stages of Baltic herring (Clupea harengus). ICES Journal of Marine Science $529 \quad 69: 529-536$.

530 Phillips MJ. 2009. Branch-length estimation bias misleads molecular dating for a vertebrate 531 mitochondrial phylogeny. Gene 441:132-140.

532 Rotondo GM, Springer VG, Scott GAJ, Schlanger SO. 1981. Plate movement and island 533

534

535 integration - a possible mechanism in the formation of endemic biotas, with special

\section{4}

536

537

538 reference to the Hawaiian islands. Systematic Biology 30:12-21.

Saitoh K, Sado T, Doosey MH, Bart HL Jr, Inoue JG, Nishida M, Mayden RL, Miya M. 2011. Evidence from mitochondrial genomics supports the lower Mesozoic of South Asia as the time and place of basal divergence of cypriniform fishes (Actinopterygii: Ostariophysi). Zoological Journal of the Linnean Society 161:633-662. DOI: 10.1111/j.10963642.2010.00651.x.

Sambrook J, Fritsch EF, Maniatis T, Others. 1989. Molecular cloning: a laboratory manual. Cold Spring Harbor Laboratory Press.

Seton M, Müller RD, Zahirovic S, Gaina C, Torsvik T, Shephard G, Talsma A, Gurnis M, Turner M, Maus S, Chandler M. 2012. Global continental and ocean basin reconstructions since 200 Ma. Earth-Science Reviews 113:212-270. DOI: 10.1016/j.earscirev.2012.03.002.

Stepien CA, Rosenblatt RH. 1996. Genetic divergence in antitropical pelagic marine fishes (Trachurus, Merluccius, and Scomber) between North and South America. Copeia 1996:586-598.

Taverne L. 2011. Les poissons crétacés de Nardò. 33 . Lecceclupea ehiravaensis gen. et sp. nov.

553 Whitehead PJP. 1964. A new genus and subgenus of clupeid fishes and notes on the genera (Teleostei, Clupeidae). Bollettino del Museo Civico di Storia Naturale di Verona 35:3Clupea, Sprattus and Clupeonella. Annals and Magazine of Natural History 7:321-330. Whitehead PJP. 1988. FAO species catalogue: an annotated and illustrated catalogue of the 

Agriculture Org.

558 Whitehead PJP, Smith PJ, Robertson DA. 1985. The two species of sprat in New Zealand waters (Sprattus antipodum and S. muelleri). New Zealand Journal of Marine and Freshwater Research 19:261-271.

Wilson AB, Teugels GG, Meyer A. 2008. Marine incursion: the freshwater herring of Lake Tanganyika are the product of a marine invasion into west Africa. PLoS One 3:e1979.

Xia X. 2013. DAMBE5: a comprehensive software package for data analysis in molecular biology and evolution. Molecular Biology and Evolution 30:1720-1728.

Xia X, Xie Z, Salemi M, Chen L, Wang Y. 2003. An index of substitution saturation and its application. Molecular Phylogenetics and Evolution 26:1-7.

Zachos J, Pagani M, Sloan L, Thomas E, Billups K. 2001. Trends, rhythms, and aberrations in

569

570

\section{Captions for Figures}

572 Figure 1. Distributional map of extant Sprattus and closely related species used in this study. Red

573 dashed line represents Sprattus fuegensis; brown is S. novaehollandiae; orange is S. muelleri;

574 light blue is S. antipodum; and green is S. sprattus. Yellow solid line represents Clupea

575 harengus; purple is C. pallasii; gray is Ramnogaster melanostoma; and blue is Strangomera

576 bentincki.

577

578 Figure 2. Bayesian consensus tree concatenating of mitochondrial genes from 750 more likely 579 trees. Branch lengths are proportional to the number of substitutions per nucleotide position.

580 Numbers at nodes are posterior probabilities from Bayesian analyses. Grey rectangles indicate 581 current hemisphere distribution. Red branches for Sprattus fuegensis, orange for S. muelleri, 582 light blue for S. antipodum, and green for S. sprattus.

583

584 Figure 3. Time-calibrated phylogenetic tree based on Bayesian relaxed-clock analyses (A) and 585 reconstruction of the ancestral geopositioned nodes $(B-G)$. Numbers at nodes are divergence 586 time since the root of each species. Horizontal colored bars indicate the 95\% HPD of divergence 
587 times, and the scale axis shows divergence times as millions of years ago (MYBP). Analyses 588 based on the topology and branch lengths of the Bayesian phylogenetic trees. Colored dots in B $589 \mathrm{G}$ correspond to posterior distribution of ancestral locations measured in longitude and latitude. 590 Colors are associated to horizontal-colored bars in (A). Paleomap reconstructions from 10, 30 , $59150,90,110$ MYBP were obtained using SETON2012 global plate motion models.

592

593

594 
Figure 1

Distributional map of extant Sprattus and closely related species used in this study.

Red dashed line represents Sprattus fuegensis; brown is S. novaehollandiae; orange is S. muelleri; light blue is $S$. antipodum; and green is $S$. sprattus. Yellow solid line represents Clupea harengus; purple is C. pallasii; gray is Ramnogaster melanostoma; and blue is Strangomera bentincki

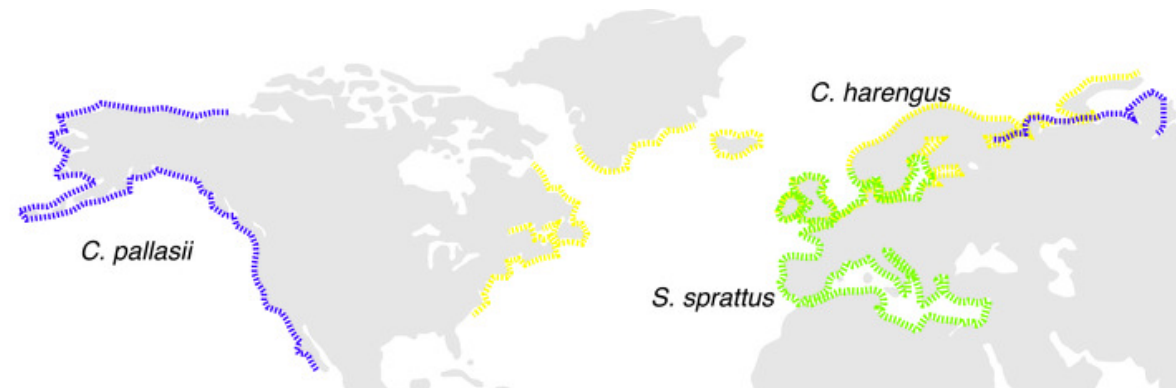

Northern Hemisphere

Southern Hemisphere

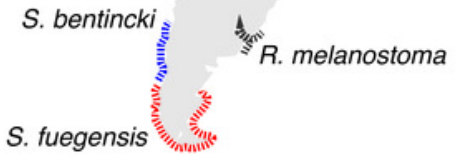


Figure 2

Bayesian consensus tree concatenating of mitochondrial genes from 750 more likely trees.

Branch lengths are proportional to the number of substitutions per nucleotide position. Numbers at nodes are posterior probabilities from Bayesian analyses. Grey rectangles indicate current hemisphere distribution. Red branches for Sprattus fuegensis, orange for S. muelleri, light blue for S. antipodum, and green for S. sprattus.

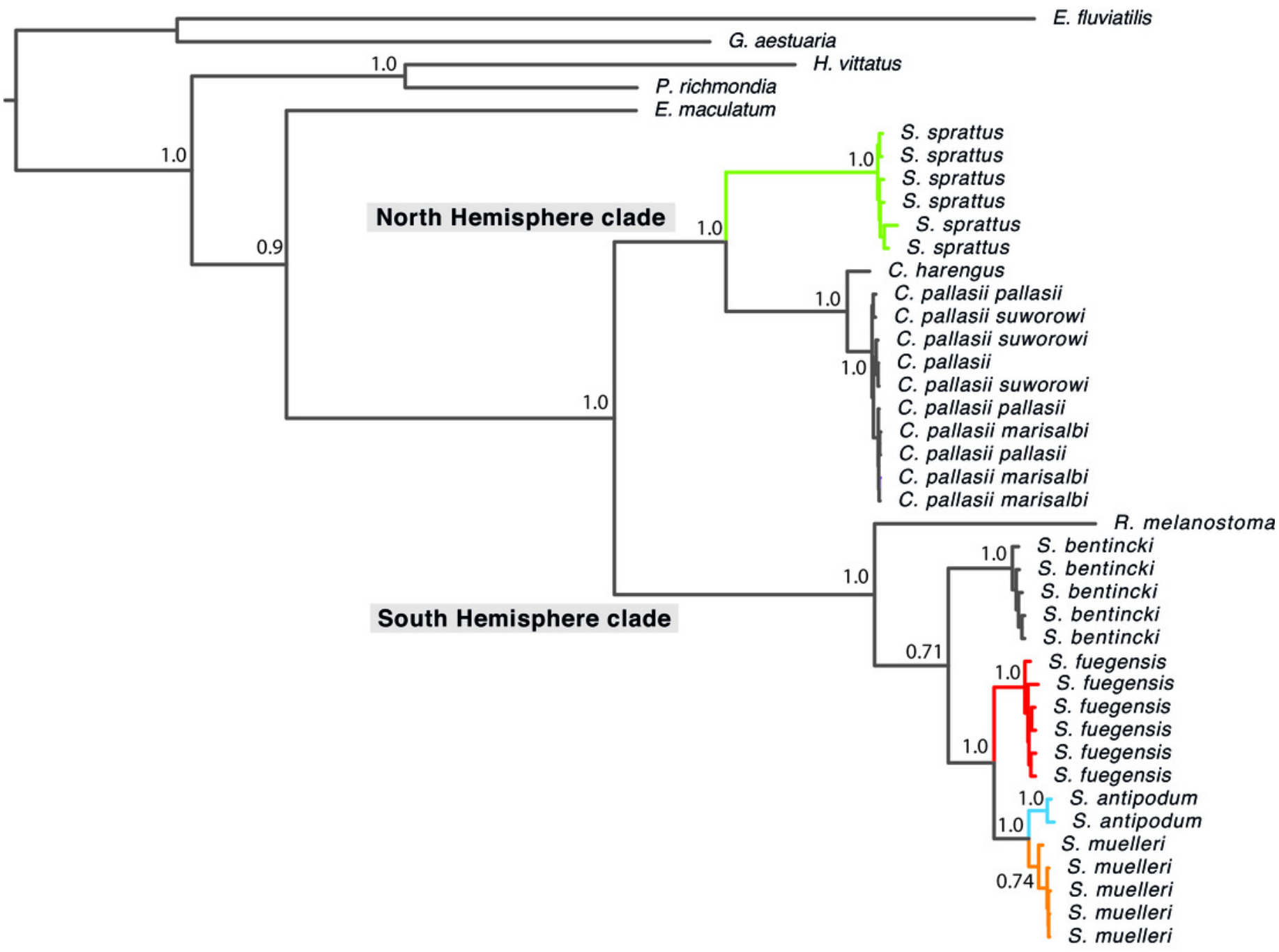




\section{Figure 3}

Time-calibrated phylogenetic tree based on Bayesian relaxed-clock analyses $(A)$ and reconstruction of the ancestral geopositioned nodes (B - G).

Numbers at nodes are divergence time since the root of each species. Horizontal colored bars indicate the 95\% HPD of divergence times, and the scale axis shows divergence times as millions of years ago (MYBP). Analyses based on the topology and branch lengths of the Bayesian phylogenetic trees. Colored dots in B - G correspond to posterior distribution of ancestral locations measured in longitude and latitude. Colors are associated to horizontalcolored bars in (A). Paleomap reconstructions from 10, 30, 50, 90, 110 MYBP were obtained using SETON2012 global plate motion models. 

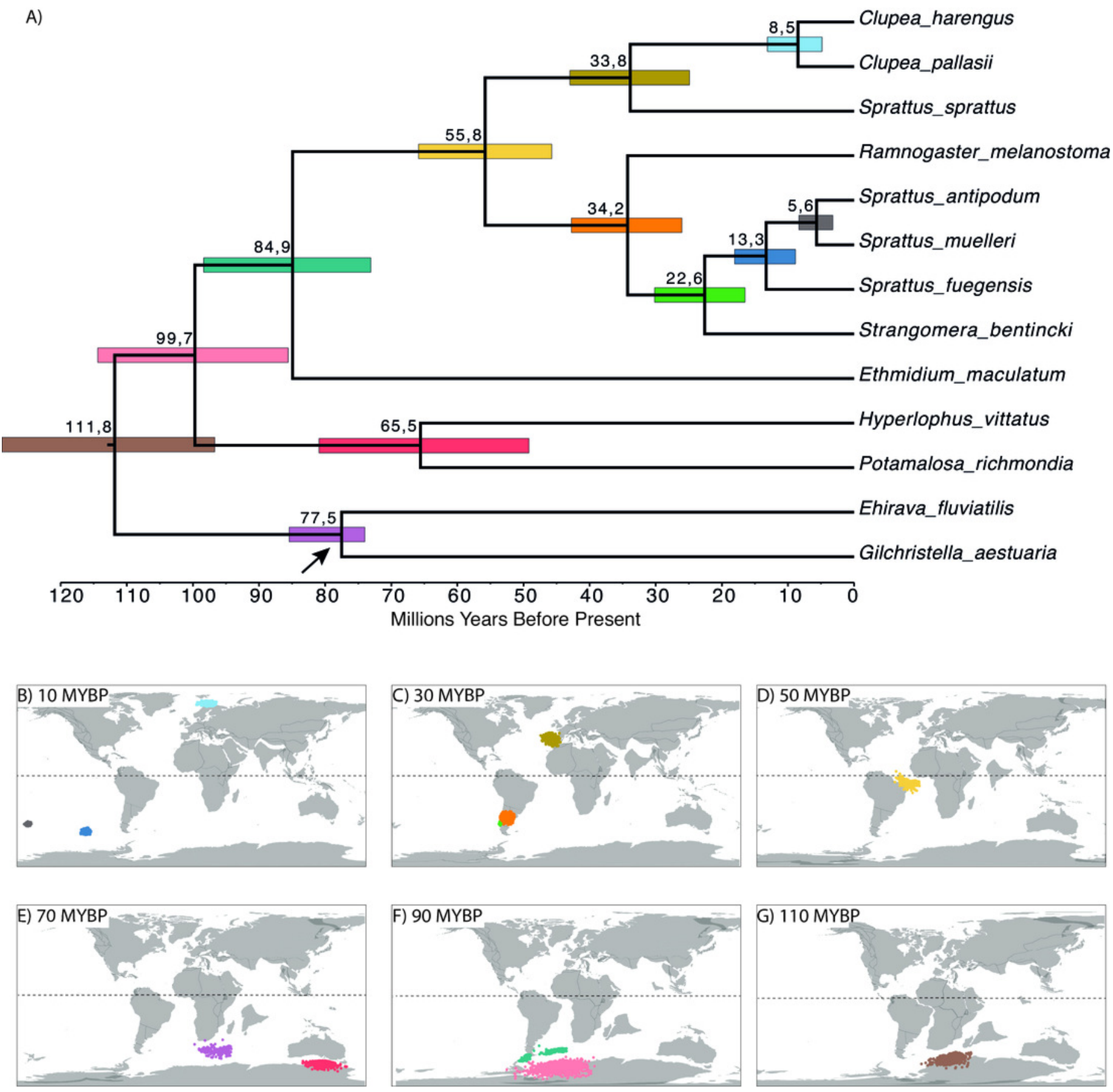